\title{
SHOPPING ORIENTATION : SEBUAH PENDEKATAN MEMPREDIKSI MINAT BELI
}

\author{
Retno Kurniasih ${ }^{1}$, Tiladela Luhita ${ }^{2 *}$, Siti Zulaikha Wulandari ${ }^{3}$ \\ 1,2,3 Jurusan Manajemen, Universitas Jenderal Soedirman \\ *Email corresponding author: tiladela.luhita@gmail.com
}

\begin{abstract}
Abstrak
Perkembangan bisnis harus disikapi secara berbeda oleh setiap pihak. Bagi konsumen, maraknya bisnis baru yang muncul semakin menguntungkan mereka, tetapi bagi pemasar pertumbuhan bisnis bisa menjadi bencana karena semakin ketatnya persaingan. Oleh karena itu pemasar harus memahami apa yang menjadi motivasi atau mendorong niat beli konsumen dan melakukan keputusan pembelian. Saat ini perkembangan bisnis batik di Indonesia sangat pesat. Pemasar batik diharuskan pintar mengolah strategi untuk bertahan di pasar, salah satunya adalah dengan mempelajari motivasi belanja konsumen. Motivasi, atau lebih dikenal dengan orientasi belanja diyakini memiliki pengaruh terhadap niat beli konsumen. Penelitian ini menggunakan 100 orang konsumen batik di Purwokerto dan sekitarnya dan regresi berganda sebagai alat analisis. Hasilnya, dari enam variabel orientasi belanja, terbukti bahwa kualitas produk dan belanja impulsif memiliki pengaruh positif terhadap minat beli konsumen.
\end{abstract}

Kata Kunci: Orientasi belanja, minat beli, batik

\begin{abstract}
Business development must be addressed differently by each party. For consumers, the emergence of new businesses benefits them, but for marketers business growth can be disastrous due to the intense competition. Therefore, marketers must understand what motivates or encourages consumer purchase intentions and make purchasing decisions. Currently the development of batik business in Indonesia is very rapid. Batik marketers are required to be smart in processing strategies to survive in the market, one of which is by studying consumer shopping motivation. Motivation, or better known as shopping orientation is believed to have an influence on consumers' purchase intentions. This study used 100 batik consumers in Purwokerto and its surroundings and multiple regression as an analytical tool. As a result, of the six shopping orientation variables, it is proven that product quality and impulsive shopping have a positive influence on consumer buying interest.
\end{abstract}

Keywords: shopping orientation, purchase intention, batik

\section{PENDAHULUAN}

Salah satu tipe industri yang saat ini sedang menjadi sorotan publik adalah industri kreatif dikarenakan jenis industri ini cenderung terlihat lebih unik dan menarik. Industri kreatif merupakan jenis industri yang memanfaatkan keterampilan, kreativitas dan bakat individu, sehingga bisa membuka lapangan pekerjaan dan meningkatkan kesejahteraan (Departemen Perdagangan RI, 2009). Di Eropa, industri kreatif lebih dikenal dengan industri budaya karena aktivitas industrinya tidak bisa lepas dari penggunaan pengetahuan. Setidaknya ada 15 sektor industri kreatif menurut Kementerian Perdagangan RI, yaitu arsitektur, seni pertunjukan, kuliner, periklanan, pasar barang seni, kerajinan, fashion, riset dan pengembangan, permainan interaktif, musik, televisi dan radio, desain, layanan komputer dan piranti lunak, serta video, film dan fotografi. Saat ini, salah satu jenis industri kreatif yang cukup mendapatkan sorotan adalah industri batik. 
Batik saat ini menjadi semakin dikenal sebagai efek dari ditetapkannya batik sebagai world cultural heritage atau warisan budaya nasional khas milik Indonesia pada 2 Oktober 2009. Keuntungan yang diperoleh pengrajin batik paska pengukuhan tersebut meningkat tajam dan banyak bermunculan jenis bisnis batik yang baru. Mengacu pada fenomena tumbuhnya industri batik, bisnis batik saat ini tidak berhenti pada kain batik saja tetapi juga merambah pada bentuk produk lain. Misalnya, baju batik, aksesori yang terbuat dari kain batik, selimut batik, pelengkap peralatan rumah tangga, dan masih banyak jenis produk turunan lainnya. Hal ini membuktikan bahwa batik merupakan industri yang potensial.

Menurut Kamar Dagang dan Industri (Wasita, 2016), industri batik di Jawa Tengah skalanya ratarata masih kecil, tetapi memiliki potensi yang sangat besar untuk dikembangkan. Misalnya pengembangan desain, pasar dan juga pemodalannya. Berdasarkan penelitian yang dilakukan oleh Zulaikha, dkk (2007), batik Banyumas mempunyai prospek yang cukup bagus. Banyumas dulu merupakan salah satu kota batik, dikarenakan kemajuan jaman dan berubahnya tren, batik di Banyumas sempat surut, tetapi saat ini banyak pebisnis batik Banyumas yang menghidupkan kembali industri batiknya. Supaya bisa bersaing dengan batik dari kota lain maka batik Banyumas harus terus dikembangkan. Oleh karena itu pengrajin dan pemasar batik harus memahami betul perilaku konsumennya.

Berdasarkan penelitian yang dilakukan oleh Luhita (2017), setidaknya terdapat dua hal yang mempengaruhi konsumen batik dalam melakukan pembelian. Dua hal tersebut, yaitu komponen sikap dan persepsi kontrol keperilakuan konsumen. Banyak peneliti yang mempelajari motivasi dan dorongan pembelian, hasilnya, konsumen termotivasi berbelanja karena ada berbagai alasan berbeda diluar keinginan untuk memperoleh produk atau jasa itu sendiri (Buttle \& Coates, 1984; Tauber, 1972; Westbrook \& Black, 1985). Motivasi berbelanja ini juga dikenal dengan istilah shopping orientation. Shopping orientation merefleksikan cara pandang konsumen mengenai perilaku belanja yang dianggap sebagai fenomena sosial, rekreasional dan ekonomi (Shim and Mahoney 1992; Hawkins et al. 2001).

Stone (1954), merupakan peneliti pertama fenomena shopping orientation membaginya menjadi empat kategori dengan nama economic, personalizing, ethical, dan apathetic shoppers. Adapun hasil studi lain yang menyebutkan orientasi belanja kenyamanan (convenience orientation), impulse buying (Bayley dan Nancorrow, 1998) dan Orientasi belanja rekreasi (recreation orientation). Mokhlis (2006) dalam penelitiannya menyebutkan tiga faktor shopping orientation, yang bernama: quality consciousness, impulsive shopping dan price consciousness. Selain itu Taks dan Shreim (2009) dalam model penelitiannya mengajukan 7 (tujuh) jenis shopping orientation yaitu Islamic obligation, Brand, Fashion, Quality, Price, Shopping enjoyment dan Impulsive shopping.

Penelitian ini dilaksanakan pada konsumen batik Banyumas dengan tujuan untuk mengetahui perilaku konsumen berdasarkan pengaruh shopping orientationnya terhadap minat beli. Selain itu, penelitian ini juga diharapkan bisa memberikan gambaran deskriptif tentang perilaku konsumen batik Banyumas.

\section{TINJAUAN PUSTAKA DAN PERUMUSAN HIPOTESIS}

Orientasi belanja adalah salah satu konsep yang paling aksiomatik dalam perilaku konsumen yang telah banyak digunakan untuk mengklasifikasikan konsumen berdasarkan kebiasaan dan gaya belanja mereka (Mokhlis, 2006). Hal ini karena orientasi belanja dianggap sebagai faktor yang paling berpengaruh yang secara langsung (Hawkins et al. 2001) atau tidak langsung melalui evaluasi konsumen terhadap atribut yang relevan, yang kemudian menjadi dasar untuk toko pilihan mereka.

Shopping Orientation adalah sebuah konsep multi-dimensi yang mencerminkan pandangan bahwa konsumen berbelanja sebagai pandangan sosial, fenomena rekreasi atau ekonomi, serta motivasi individu untuk belanja (Shim dan Mahoney 1992; Hawkins et al, 2001.). Dasar pemikiran dari konsep ini adalah bahwa konsumen mempunyai pendekatan yang berbeda untuk belanja berdasarkan pengalaman belanja masa lalu mereka (Darden dan Dorsch 1990). Dengan demikian, orientasi belanja dapat dianggap sebagai karakteristik individu yang cenderung mengarah pada tindakan belanja. Beberapa peneliti 
menyepakati bahwa pemasar, perlu memahami psikografis dan orientasi belanja konsumen, agar dapat memaksimalkan kepuasan konsumen dan penjualan. Oleh karena itu studi tentang shopping orientation akan bermanfaat bagi pemasar dalam menyesuaikan strateginya dengan kebutuhan konsumen. Ini merupakan sesuatu yang penting, dimana pemasar dapat mengkaitkan keragaman shopping orientation dengan perilaku pasar.

Visser dan du Preez (2001) menunjukkan bahwa konsep orientasi belanja terdiri dari Personal dimension (misalnya: aktivitas, minat, pendapat, motif, kebutuhan dan preferensi) dan dimensi perilaku pasar mencerminkan dimensi pribadi dan menunjukkan kebutuhan serta preferensi, antara lain, sumbersumber informasi, dan citra toko (termasuk atribut toko). Orientasi belanja dioperasionalkan oleh berbagai kegiatan, minat dan pernyataan pendapat yang relevan dengan tindakan belanja. Kecenderungan orientasi belanja ini mengarah ke dalam bentuk tindakan belanja yang dilakukan oleh konsumen, misalnya dalam bentuk kegiatan pencarian informasi, evaluasi alternatif, dan pemilihan produk.

Pardede, dkk (2016) meneliti hubungan orientasi belanja terhadap niat beli konsumen online di Tokopedia. Metode yang digunakan dalam penelitian tersebut adalah metode kuantitatif dengan sample sebanyak 385 responden. Hasil dari penelitian tersebut menunjukan bahwa orientasi belanja memiliki pengaruh terhadap minat beli konsumen Tokopedia. Kusuma \& Berlian (2013) mengungkapkan dalam penelitiannya bahwa beberapa bagian dari orientasi belanja memiliki pengaruh terhadap minat belit, yaitu orientasi shopping enjoyment, convenience/time consciousness dan in-home shopping tendency. Ling, dkk (2010) menemukan bahwa orientasi belanja memiliki pengaruh terhadap minat beli konsumen. Penelitian ini dilakukan pada konsumen online, yaitu 242 orang mahasiswa jurusan Teknologi Informasi di beberapa universitas swasta di Malaysia. Berdasarkan penjelasan diatasa, hipotesis yang dirumuskan adalah sebagai berikut:

$\mathrm{H}_{1} \quad$ : Kesadaran merk berpengaruh positif terhadap minat beli batik.

$\mathrm{H}_{2} \quad$ : Kenikmatan belanja berpengaruh positif terhadap minat beli batik.

$\mathrm{H}_{3} \quad$ : Kesadaran mode berpengaruh positif terhadap minat beli batik.

$\mathrm{H}_{4} \quad$ : Kesadaran kualitas berpengaruh positif terhadap minat beli batik.

$\mathrm{H}_{5} \quad$ : Belanja impulsif berpengaruh positif terhadap minat beli batik.

$\mathrm{H}_{6} \quad$ : Kesadaran harga berpengaruh positif terhadap minat beli batik.

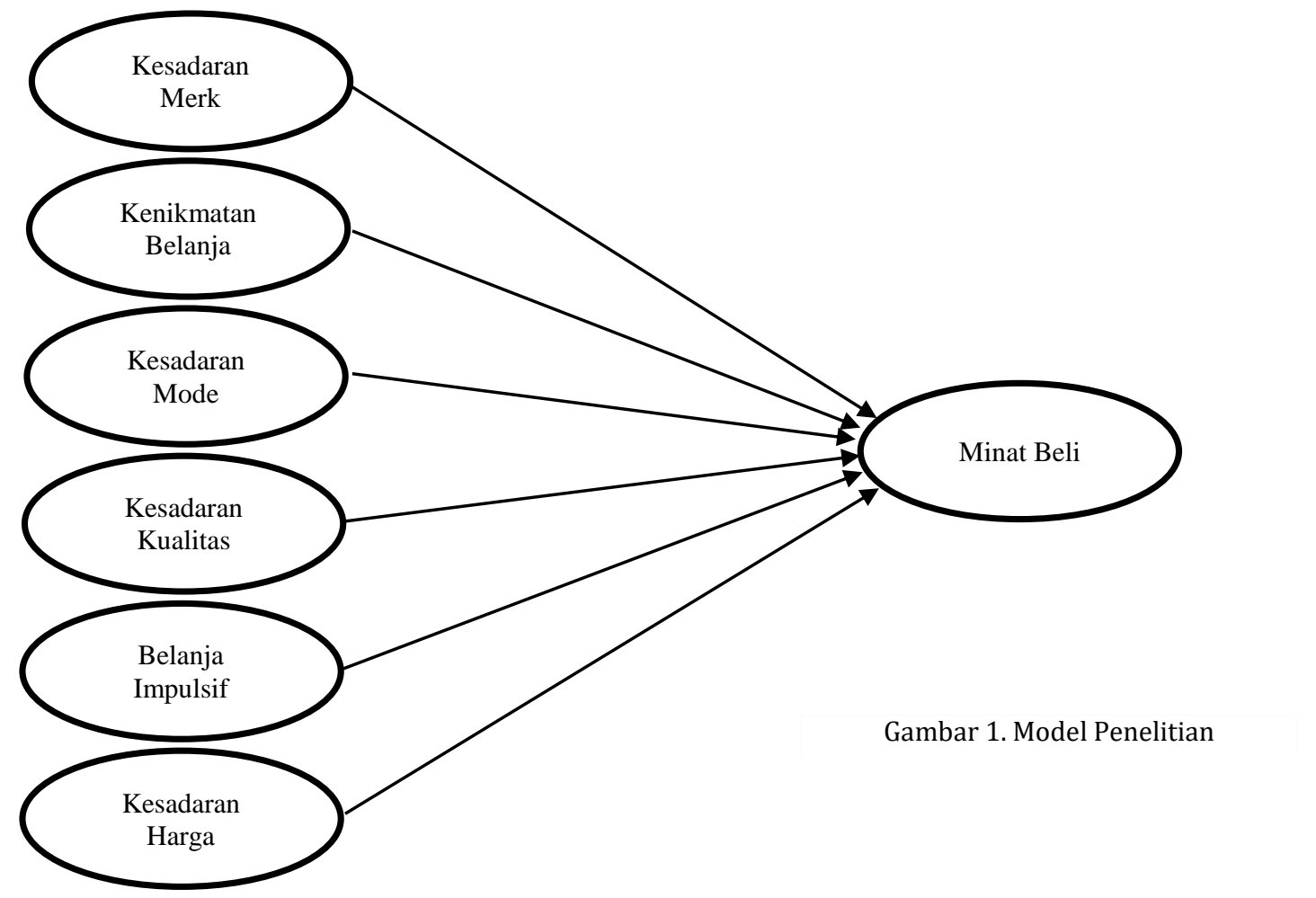




\section{METODE PENELITIAN}

Penelitian ini merupakan penelitian kuantitatif yang bertujuan untuk menguji pengaruh shopping orientation terhadap minat beli konsumen batik. Penelitian dilakukan di Kabupaten Banyumas, dengan pemilihan area terbatas, yaitu di sekitar kota Purwokerto. Populasi yang menjadi target dalam penelitian adalah konsumen produk batik yang ada di kota Purwokerto. Sampel dalam penelitian ini ditentukan dengan teknik non probability sampling, yaitu dengan metode purposive sampling, dimana sampel penelitian dipilih secara subyektif berdasarkan kriteria dan pertimbangan tertentu yang relevan dengan penelitian. Pertimbangan yang dipergunakan dalam penelitian ini yaitu responden merupakan konsumen pengguna produk batik, yang berada di lokasi tempat penjualan batik di wilayah sekitar Purwokerto, pernah berbelanja produk batik setidaknya satu kali dan telah mampu melakukan keputusan pembelian secara mandiri (berusia 15 tahun keatas). Dalam penelitian ini, besarnya populasi tidak diketahui secara pasti, sehingga penentuan ukuran sampel minimal dilakukan dengan cara menaksir proporsi jumlah obyek yang akan diteliti. Adapun sample akhir yang harus dipenuhi yaitu 100 orang responden.

\section{HASIL DAN PEMBAHASAN}

Instrumen penelitian telah melewati tahap uji validitas dan reliabilitas. Keduanya diuji menggunakan, berturut-turut, product moment dan cronbach alpha. Selain itu, uji asumsi klasik dilakukan untuk memastikan bahwa persamaan regresi yang digunakan tepat, konsisten dan juga tidak bias. Total kuesioner yang disebarkan yaitu sebanyak 110 kuesioner. Terdapat 7 (tujuh) buah kuesioner yang tidak kembali atau kembali tetapi tidak dapat dipakai karena ketidaklengkapan isi dan faktor lain. Oleh karena itu, diketahui bahwa tingkat pengembalian kuesioner mencapai 93,64\% yang kembali dan lengkap serta layak untuk diolah.

Hasil uji statistik yang dilakukan pada hipotesis pertama yang menyebutkan bahwa kesadaran merk mempunyai pengaruh yang positif terhadap minat beli konsumen batik dinyatakan ditolak. Secara teoritis, konsumen akan cenderung lebih memilih merk batik tertentu yang sudah dikenal konsumen sebelumnya. Tetapi dalam kasus penelitian ini, yang menjadi permasalahan adalah di daerah Banyumas belum terdapat merk-merk batik yang cukup dikenal oleh konsumen. Dibandingkan di kota besar yang sudah banyak pilihan merk batik, di Banyumas sendiri konsumen belum menyatakan bahwa mereka cukup familiar bahwa batik mempunyai merk. Responden ketika ditanya mengenai seberapa familiar mereka dengan merk batik lokal, sebagian besar menyatakan bahwa mereka tidak tahu bahwa batik memiliki merk tertentu. Sehingga alih-alih memilih merk yang sebenarnya mereka pun tidak tahu eksistensinya, responden lebih mempertimbangkan kategori produk yang sesuai dengan keinginan, kemampuan, dan selera konsumen. Hasil penelitian ini tidak sejalan dengan hasil penelitian yang dilakukan oleh Yaseen et. al (2011) mengenai pengaruh brand awareness terhadap purchase intention pada produk retail khususnya merk kosmetik seperti L'oreal dan Garnier. Perbedaan penelitian ini dikarenakan kondisi dilapangan yang cukup berbeda. Pada penelitiannya, Yaseen et al (2011) menggunakan produk yang merk-nya sudah sangat dikenal oleh konsumen dan konsumen produk retail kosmetik tersebut sangat memahami perbedaan antara merk satu dengan yang lain. Tidak seperti konsumen batik yang belum terlalu familiar dengan merk batik.

Hasil uji statistik yang dilakukan pada hipotesis kedua yang menyebutkan bahwa kenikmatan belanja mempunyai pengaruh yang positif terhadap minat beli konsumen batik dinyatakan ditolak. Bagi konsumen, berbelanja batik bukanlah sebuah kegiatan bersosialiasi untuk menghilangkan kejenuhan. Responden mengungkapkan bahwa minat beli mereka terhadap batik ditujukan untuk memenuhi kebutuhkan mereka akan produk batik. Hal ini dikarenakan sebagian konsumen berstatus sebagai pegawai, baik pegawai pemerintah maupun pegawai swasta. Terdapat anjuran dari berbagai instansi untuk menggunakan batik pada hari yang telah ditentukan. Hasil penelitian tidak sejalan dengan Seock dan Bailey (2008). Salah satu kemungkinan yang membuat hasil penelitian berbeda adalah perbedaan responden. Pada penelitiannya Seock dan Bailey (2008) hanya menggunakan mahasiswa sebagai responden, berarti responden ada pada kisaran usia 18-25 tahun. Berdasarkan kutipan dari Parekh (2007) mengindikasikan bahwa perusahaan lebih baik menggunakan strategi pemasaran yang diselipi 
penggunaan humor dan lebih interaktif untuk konsumen mahasiswa. Hal ini menunjukan bahwa mahasiswa cenderung menikmati proses pembelian, oleh karena itu perusahaan harus melakukan trik khusus agar mahasiswa merasa senang dalam proses membeli. Berbeda dengan penelitian ini yang dilakukan dengan responden dalam rentang umur yang cukup luas. Oleh karena itu terdapat variasi jawaban yang lebih luas apabila dibandingkan dengan penelitian sebelumnya.

Hasil uji statistik yang dilakukan pada hipotesis ketiga yang menyebutkan bahwa kesadaran mode mempunyai pengaruh yang positif terhadap minat beli konsumen batik dinyatakan ditolak. Menurut Michaela dan Orna (2015), konsumen dengan kesadaran mode merupakan salah satu konsumen yang paling potensial untuk dijadikan target pasar, terlebih untuk produk-produk fashion. Hal ini dikarenakan konsumen yang memiliki tingkat kesadaran mode yang tinggi cenderung lebih tertarik untuk mengikuti tren yang sedang diminati oleh konsumen. Mereka akan menghabiskan lebih banyak waktu untuk mencari-cari informasi yang berhubungan dengan mode terbaru, berbelanja lebih sering, dan mencoba lebih banyak item fashion terbaru (Bertrandias \& Goldsmith, 2006; Iver \& Eastman, 2010). Pada penelitian ini, responden menyatakan bahwa mereka tidak terlalu memperhatikan mode batik terbaru. Bagi konsumen batik, mode terbaru tidaklah terlalu penting dikarenakan corak batik sudah sangat beragam. Bahkan beberapa responden menyatakan lebih menyukai corak dan motif batik klasik yang cukup lawas dibandingkan motif dan corak yang lebih up to date. Pada penelitiannya, Michaela dan Orna (2015) mengkonfirmasi adanya hubungan yang positif pada kesadaran mode terhadap minat beli konsumen. Perbedaan ini dikarenakan penelitian tersebut diterapkan pada produk fashion secara umum, sedangkan penelitian ini secara khusus dan spesifik meneliti produk fashion batik. Selain itu, temuan ini mendukung penelitian yang dilakukan oleh Bakewel, et. al. (2006) yang menyatakan bahwa walaupun diidentifikasi terdapat fashion consiousness yang tinggi, tidak membuktikan hal tersebut selalu berakhir pada fashion adoption.

Hasil uji statistik yang dilakukan pada hipotesis keempat yang menyebutkan bahwa kesadaran kualitas mempunyai pengaruh yang positif terhadap minat beli konsumen batik dinyatakan diterima. Kesadaran kualitas berarti seseorang paham tentang karakter dan atribut apa saja yang membuat sebuah produk masuk dalam kategori kualitas tinggi dan kekurangan apa yang membuat produk bisa saja masuk dalam kategori berkualitas rendah. Penelitian ini membuktikan bahwa konsumen produk batik cukup sadar dengan kualitas batik yang dibelinya. Responden menilai bahwa terdapat perbedaan yang cukup mudah diidentifikasi antara batik dengan kualitas rendah, medium, dan tinggi. Telah cukup dipahami konsumen bahwa batik yang berkualitas memiliki serat kain yang halus dan kuat. Walaupun tekstil dasar batik tersebut kuat, tetapi ketika diproduksi menjadi pakaian, batik tersebut tidak kaku dan cukup nyaman dipakai. Selain itu, dari segi pewarnaannya, baik batik yang berkualitas baik maupun yang rendah keduanya harus dilihat dari beberapa kali proses pencucian. Biasanya batik dengan kualitas yang cukup baik, walaupun "luntur" saat beberapa kali proses pencucian pertama, warna asli tetap terlihat jelas dan tidak ada residu yang tertinggal setelah pencucian. Untuk produk batik dalam bentuk pakaian, jahitan biasanya lebih halus, rapi, kuat dan simetris. Berbeda dengan pakaian batik dengan kualitas rendah, biasanya kualitas jahitan pun berbeda. Bisa jadi jahitan yang tidak simetris, banyak benang terlepas setelah beberapa kali pakai, dan kasus lain. Karakter tersebut yang meningkatkan minat konsumen dalam melakukan pembelian batik. Konsumen menjadi berminat membeli batik saat mereka yakin bahwa batik tersebut memang pada taraf kualitas yang mereka inginkan. Penelitian ini mendukung temuan dari Kwek et. al, (2010) yang menyatakan bahwa faktor kualitas merupakan salah satu faktor yang paling dipertimbangkan oleh konsumen dalam melakukan pembelian. Konsumen akan semakin memiliki minat beli yang lebih besar apabila konsumen paham terntang kualitas produk tersebut.

Hasil uji statistik yang dilakukan pada hipotesis kelima yang menyebutkan bahwa belanja impulsif mempunyai pengaruh yang positif terhadap minat beli konsumen batik dinyatakan diterima. Konsumen yang terlibat dalam proses belanja yang bersifat impulsif sebelumnya tidak memiliki rencana sama sekali akan melakukan pembelian tersebut, dorongan untuk membeli datang secara tiba-tiba dan evaluasi pembelian tidak bersifat substantif (Rook, 1987). Penelitian ini menemukan adanya hubungan yang positif antara impulse buying dengan minat beli. Konsumen menyatakan bahwa seringkali pembelian batik dilakukan tanpa rencana dan dorongan tersebut tiba-tiba saja datang. Beberapa faktor yang menurut penilaian responden mempengaruhi mereka adalah kondisi toko dan faktor eksternal lain. Ketika responden mengunjungi toko, dikemukakan bahwa mereka senang melihat kain batik yang 
tertata rapi berdasarkan warnanya dan juga motif yang ter-display dengan baik. Hal tersebut terbukti sangat menstimulus minat beli konsumen. Faktor eksternal lain yang mempengaruhi konsumen adalah cara berpromosi yang menarik. Seperti yang diungkapkan oleh Schiffman (2010), untuk era saat ini sangat cocok apabila produsen menggunakan teknik promosi yang inovatif, kreatif dan diiringi dengan penggunaan teknologi. Sama halnya yang responden alami, terkadang responden mengisi waktu senggangnya dengan melihat-lihat produk melalui internet dan berakhir dengan membeli barang yang sebelumnya mereka tidak rencanakan dikarenakan promosi yang menarik. Hasil penelitian ini mendukung temuan dari Drossos, et. al (2014) yang menyatakan bahwa pembelian impulsif bisa menjadi indikator minat beli konsumen pada sebuah produk.

Hasil uji statistik yang dilakukan pada hipotesis keenam yang menyebutkan bahwa kesadaran harga mempunyai pengaruh yang positif terhadap minat beli konsumen batik dinyatakan ditolak. Konsumen dengan kesadaran harga yang tinggi akan sebisa mungkin mencari alternatif produk dengan selisih harga yang jauh dari produk sejenisnya. Sebaliknya, konsumen dengan kesadaran harga yang rendah tidak akan menghabiskan terlalu bayak waktu untuk mencari harga terendah. Hasil penelitian ini menunjukan bahwa pada konsumen batik tidak terdapat korelasi positif antara kesadaran harga dengan minat beli. Hal ini berarti konsumen batik cenderung tidak mencari alternatif harga yang paling rendah untuk produk batik. Konsumen batik menyadari bahwa batik memerlukan proses yang cukup panjang dalam pembuatannya, konsumen memahami mengapa penjual batik mematok harga yang tidak murah. Berbeda dengan kain tekstil pada umumnya yang selesai hanya dalam satu kali proses printing, contohnya untuk batik tulis membutuhkan tujuh tahap pembuatan dari nglowong, yaitu menggambar kain menggunakan lilin sampe dengan nglorot, yaitu membersihkan seluruh lilin tersebut.

\section{KESIMPULAN}

Berdasarkan hasil penelitian yang telah dilakukan dengan pengambilan data kemudian dilanjutkan dengan analisis data, beberapa temuan didapatkan dan beberapa implikasi bisa ditawarkan bagi pelaku bisnis batik. Penelitian ini menemukan bahwa dua hal dari shopping orientation yang terbukti mempunyai pengaruh positif terhadap minat beli adalah kesadaran kualitas (quality consciousness) dan belanja impulsif (impulse buying). Pelaku bisnis harus menyikapi temuan tersebut dengan cara memperhatikan kualitas produk batiknya. Misalnya dengan mengkategori dengan jelas antara batik berkualitas tinggi, sedang dan rendah. Hal ini akan mempermudah pelanggan dalam memilih kelas kualitas yang dibutuhkan. Temuan kedua yang harus disikapi dengan bijak oleh pelaku bisnis adalah strategi untuk meningkatkan impulse buying konsumen. Sebelumnya konsumen menyatakan bahwa beberapa hal yang memicu pembelian yang tidak direncanakan adalah kondisi toko dan trik promosi. Oleh karena itu, pelaku bisnis sebaiknya mulai memikirkan layout toko yang atraktif. Misalnya batik dengan warna yang sama dikumpulkan dengan warna yang sejenis. Kemudian display kain batik dengan posisi yang memungkinkan motifnya terlihat menarik. Selain itu, promosi yang menarik juga sangat dipertimbangkan konsumen. Seperti penggunaan teknologi media sosial, konten grafis yang menarik, dan berbagai macam cara lain yang bisa memotivasi keinginan beli konsumen.

\section{DAFTAR PUSTAKA}

Bakewell, C., Mitchell, V.W,. and Morgan Rothwell. (2006). UK Generation Y male fashion consciousness. Journal of Fashion Marketing and Management: An International Journal. Volume 10 Issue 2.pp. $169-180$.

Bertrandias, L., \& Goldsmith, R. E. (2006). Some psychological motivations for fashion opinion leadership and fashion opinion seeking. Journal of fashion marketing and management Vol 10. No 1, 22-40.

Buttle, F., \& Coates, M. (1984). Shopping Motives. The Service Industries Journal, 4(1), 71-82.

Darden, W. R., \& Dorsch, M. J. (1990). An action strategy approach to examining shopping behavior. Journal of Business Research, 21(3), 289-308.

Departemen Perdagangan Republik Indonesia. 2009. Studi Industri Kreatif. 
Drossos, A.D., et al. (2014). The effects of product involvement and impulse buying on purchase intentions in mobile text advertising. Electronic Commerce Research and Applications. Volume 13, Issue 6.

Hawkins, Best, Coney. (2001). Consumer Behavior Building Marketing Strategy. 8th ed, McGraw-Hill, Boston

Iver, r., \& Eastman, J. (2010). The fashion conscious mall shopper; An exploratory study. The marketing management journal vol 20 issue 2, 42-53.

Kusuma, D, dan Berlian S. (2013). Pengaruh Orientasi Belanja Terhadap Intensi Pembelian Produk Pakaian Secara Online pada Pengguna Online Shop. JURNAL Psikologi Industri dan Organisasi Vol 02, No. 1.

Kwek, C. L., et. al. (2010). Investigating the Shopping Orientations on Online Purchase Intention in the eCommerce Environment: A Malaysian Study. Journal of Internet Banking and Commerce 15(2):122

Ling, Kwek C. (2010). The Effects of Shopping Orientations, Online Trust and Prior Online Purchase Experience toward Customers. Online Purchase Intention. International Business Research Vol. 3, No. 3.

Luhita, Tiladela, Retno Kurniasih dan Asteria P. (2017). Analisis Perilaku Pembelian dalam Keputusan Pembelian Produk Kain Batik Tulis Banyumas. Penelitian (tidak dipublikasikan)

Michaela, Elram dan Orna, S.L. (2015). Fashion Conscious Consumers, Fast Fashion and the Impact of Social Media on Purchase Intention. Academic Journal of Interdisciplinary Studies. Vol 4. No 3.

Mokhlis, Safiek. (2006). The Effect of Religiosity on Shopping Orientation: An Exploratory Study in Malaysia. Journal of American Academy of Business. Cambridge.

Pardede, Sanggam dan Erni Martini. (2016). Pengaruh Orientasi Belanja Terhadap Minat Beli Online Pada Konsumen Tokopedia.Com di Indonesia. e-Proceeding of Management: Vol.3

Rook, D.W. (1987). The buying impulse. Journal of Consumer Research, 14(2), 189-199.

Rupal Parekh. (2007). Febreze Sniffs Out New Target: Dorm Dwellers. Advertising Age, 12.

Seock, Yoo-Kyoung and Bailey, L.R. (2008). The influence of college students' shopping orientations and gender differences on online information searches and purchase behaviors. International Journal of Consumer Studies, 32, 113-121.

Shim, S. and Mahoney, M. Y. (1992). The Elderly Mail-Order Catalog User of Fashion

Stone, G.P. (1954). City and urban identification: Observations on the social psychology of city life. The American Journal of Sociology. 60. 36-45.

Taks, M., \& Shreim, M. (2009). The influence of Islam on shopping behavior for sports apparel: An empirical study of Muslim immigrants. In 17TH EASM CONFERENCE. Amsterdam: EASM.

Tauber, E.M. (1972) Why do people shop? Journal of Marketing, 36 (4), 46-49.

Visser,E.M., Preez,R. (2001). Apparel shopping orientation Two decades of research, Journal of Family Ecology and Consumer Sciences, 29, 72 -81. 
Wasita, Aris. (2016). Meski Skala Kecil, Industri Batik Jateng Memiliki Potensi Besar. https://jateng.antaranews.com/detail/meski-skala-kecil-industri-batik-jateng-memilikipotensi-besar.html diakses 27 November 2017

Westbrook, R. A., \& Black, W. C. (1985). A motivation-based shopper typology. Journal of Retailing, 61(1), 78-103.

Wulandari, Siti Zulaikha, Weni Novandari dan Refius P. Setyanto. (2007). Analisis Faktor Kendala dan Kelayakan Usaha Pada Industri Batik Banyumas. Penelitian (tidak dipublikasikan).

Yaseen, Nazia et al. 2011. Impact of Brand Awareness, Perceived Quality and Customer Loyalty on Brand Profitability and Purchase Intention: A Resellers' View. Interdicipinary Journal of Contemporary Research in Business. Vol 3, No 8. 